\title{
Eficácia do imazapic no controle de capim-camalote aplicado em solos de diferentes texturas ${ }^{1}$
}

\section{Imazapic effectiveness in itchgrass control applied in different soil textures}

\author{
Ana Carolina Dias Guimarães ${ }^{2}$; Vanessa Takeshita ${ }^{3}$; Fabrício Catissi $^{4}$; Marcelo Nicolai ${ }^{5}$; Pedro \\ Jacob Christoffoleti ${ }^{6}$
}

\begin{abstract}
Resumo - O capim-camalote (Rottboelia exaltata L.f.) é uma planta daninha com rápida capacidade de disseminação nas áreas canavieiras do Brasil, causando significativas perdas de produtividade na cultura. Assim, esta pesquisa teve como objetivo avaliar a suscetibilidade do capim-camalote ao herbicida imazapic, quando aplicado em pré-emergência, por meio de curvas de dose-resposta. $\mathrm{O}$ experimento foi desenvolvido no delineamento experimental do tipo blocos ao acaso com quatro repetições em esquema fatorial entre dois tipos de solo (franco argilo-arenoso e franco arenoso) e nove doses do herbicida imazapic. As doses utilizadas foram: 0; 9,19; 18,38; 36,$75 ; 50 ; 73 ; 147 ; 294 ; 588$ e 1176 g i.a. ha ${ }^{-1}$ e testemunha sem aplicação. O uso do imazapic causou maior controle e menor matéria seca do capim-camalote quando aplicado em solo franco arenoso, em relação ao solo franco argilo-arenoso. A textura do solo tem influência direta na eficiência de controle, de modo que a dose de $18,38 \mathrm{~g}$ i.a. ha ${ }^{-1}$ demonstrou maior controle do capimcamalote em solo franco arenoso, já para solo franco argilo-arenoso foi de $294 \mathrm{~g}$ i.a. ha ${ }^{-1}$. Os níveis de controle indicam a viabilidade de aplicação de imazapic em pré-emergência para controle do capim-camalote.
\end{abstract}

Palavras-chaves: dose-resposta; imidazolinonas; pré-emergência; Rottboelia exaltata L.f.

\begin{abstract}
Itchgrass (Rottboelia exaltata L.f.) is a weed that presented fast dissemination in sugarcane fields in Brazil, causing significant yield losses to the crop. Therefore, this research had the objective of evaluating the susceptibility of the weed itchgrass to imazapic when applied in preemergence using dose-response curves. The experiments were carried out in randomized blocks experimental design with four replications in a factorial arrangement between two soil (clayeysandy and sandy) and nine rates of imazapic. The herbicide rates were: $0 ; 9.19 ; 18.38 ; 36.75 ; 50$; 73; 147; 294; 588 and $1176 \mathrm{~g}$ a.i. $\mathrm{ha}^{-1}$ and check without application. The sandy soil scored by visual control upper and lower levels of residual dry matter compared to the clayey-sandy soil. Soil texture has a direct influence on the effectiveness of control. Soil texture has a direct influence on control efficiency, so that the dose of $18.38 \mathrm{~g}$ a.i. $\mathrm{ha}^{-1}$ showed more control of itchgrass in sandy

\footnotetext{
${ }^{1}$ Recebido para publicação em 28/01/2016 e aceito em 01/06/2016.

${ }^{2}$ Professora Adjunta da Universidade do Estado de Mato Grosso - UNEMAT, Alta Floresta, Mato Grosso, Brasil. Email: <acrdias@unemat.br>.

${ }^{3}$ Graduanda em Engenharia Agronômica da Universidade do Estado de Mato Grosso - UNEMAT, Alta Floresta, Mato Grosso, Brasil. E-mail: <vanessa_takeshita@ hotmail.com>.

${ }^{4}$ BASF S.A., Ribeirão Preto, São Paulo, Brasil. E-mail: <fabricio.catissi@basf.com>.

5 Pesquisador, Doutor, Agrocon Assessoria Agronômica, Santa Bárbara d`Oeste, São Paulo, Brasil. E-mail: <mnicolai2009@gmail.com>.

${ }^{6}$ Professor Associado do Departamento de Produção Vegetal, Escola Superior de Agricultura "Luiz de Queiroz", Universidade de São Paulo, Piracicaba, São Paulo, Brasil. E-mail: <pedrochristoffoleti@ gmail.com>.
} 
soil, while for clay and sandy soil was $294 \mathrm{~g}$ a.i. ha ${ }^{-1}$. Control levels indicate that application of imazapic in pre-emergence is viable to control the weed itchgrass.

Keywords: dose-response; imidazolinones; pre-emergence; Rottboelia exaltata L.f.

\section{Introdução}

As plantas daninhas são um dos principais fatores bióticos presentes no agroecossistema da cana-de-açúcar com capacidade de interferir no desenvolvimento e na produtividade da cultura (Figueiredo et al., 2013), podendo gerar cerca de $40 \%$ de redução na produtividade, quando comparado a ausência destas plantas (Kuva et al., 2003; Silva et al., 2009). Dentre as infestantes causadoras de perdas no rendimento da cultura da cana-deaçúcar destaca-se o capim-camalote.

O capim-camalote (Rottboelia exaltata L.f.) é uma planta daninha originária da Ásia, e no Brasil ocorre com maior frequência na Região Norte, contudo, existem focos de ocorrência no Estado de São Paulo e na Região Centro-Oeste (Carvalho et al., 2005). É pertencente à família Poaceae, possui ciclo anual ou perene, dependendo das condições ambientais. Dentre as plantas daninhas que mais competem com a lavoura canavieira destaca-se o capim-camalote que, em densidades maiores que 10 plantas por $\mathrm{m}^{2}$, não permite $\mathrm{o}$ desenvolvimento pleno das plantas de cana-deaçúcar (Oliveira e Freitas, 2009).

O capim-camalote tem vigoroso crescimento vegetativo e rápido ciclo reprodutivo, altamente capaz em emitir estruturas reprodutivas e produzir propágulos ao longo de todo o seu ciclo, sendo também muito oportunista quanto ao seu processo de enraizamento (Carvalho et al., 2005). É considerada uma planta prolífica, sendo que em uma única planta chega a emitir até 100 perfilhos, capazes de produzir 15.000 sementes que podem ficar dormentes nos solos por até quatro anos. Devido à sua elevada adaptabilidade ecológica, apresenta ocorrência nos mais diversos ambientes produtivos (Lorenzi, 2014).
Para a eficiência no controle de plantas daninhas no período crítico de competição destas com a cultura, um dos fatores determinantes é a utilização de herbicidas préemergentes com efeito residual prolongado (Monquero et al., 2008). Como é o caso do herbicida imazapic, pertencente ao grupo das imidazolinonas, sendo um inibidor da enzima ALS, que atua no sítio de ligação deste substrato que regula a produção dos aminoácidos valina, leucina e isoleucina, ocasionando reflexos negativos na síntese de proteínas, diminuição da translocação de açúcares para as regiões de demanda da planta e pela inibição da mitose (Vidal et al., 2014).

A recomendação adequada das doses de herbicida, com maior eficiência no controle das plantas daninhas, depende da interação soloplanta-herbicida onde no solo, está relacionado com a dissipação dos herbicidas por meio de processos e velocidades distintas, influenciadas pelas propriedades físico-químicas da molécula, pelos atributos do solo, pelas condições ambientais ou pela interação desses fatores (Christoffoleti et al, 2009).

Deste modo, esta pesquisa teve por objetivo avaliar a suscetibilidade da planta daninha capim-camalote (Rottboelia exaltata) ao herbicida imazapic, quando aplicado em préemergência, por meio de curvas de doseresposta em solos de diferentes texturas.

\section{Material e Métodos}

O experimento foi instalado em casa de vegetação do Departamento de Produção Vegetal da Escola Superior de Agricultura "Luiz de Queiroz" - ESALQ/USP, em Piracicaba - SP - Brasil (22 42' 30" latitude sul, $47^{\circ} 38^{\prime} 00^{\prime \prime}$ longitude oeste e $546 \mathrm{~m}$ de altitude), no período compreendido entre abril a agosto de 2009, sendo desenvolvido no delineamento experimental em blocos ao acaso com quatro 
repetições em esquema fatorial $2 \times 9$. O primeiro fator consistiu de nove doses de imazapic (147 g i.a. ha ${ }^{-1}$ ) (Plateau, $700 \mathrm{~g} \mathrm{~kg}^{-1}$, WG, BASF S.A.), sendo $0 ; 9,19 ; 18,38 ; 36,75 ; 50 ; 73 ; 147$; 294; 588 e 1176 g i.a. ha ${ }^{-1}$. O segundo fator foi composto por dois solos de textura contrastante (textura argilo-arenosa e arenosa). As sementes de capim-camalote foram coletadas em área produtora de cana-de-açúcar na região do município de Campos dos Goytacazes, Estado do Rio de Janeiro.

As parcelas constaram de vasos plásticos com capacidade para 1,1 L, preenchidos com solo de textura franco argilo-arenoso ou com solo franco arenoso, devidamente fertilizado com 1 grama da fórmula 10-10-10 $\left(\mathrm{N}-\mathrm{P}_{2} \mathrm{O}_{5}-\right.$
$\mathrm{K}_{2} \mathrm{O}$ ) e acrescido de 1 grama de sementes de capim-camalote. A análise química e física do solo é visualizada na Tabela 1.

A aplicação dos tratamentos foi realizada logo após a semeadura, com auxílio de pulverizador costal pressurizado por $\mathrm{CO}_{2}$, acoplado a lanço com uma ponta do tipo leque com jato plano, modelo XR 110.02, calibrado para volume de calda correspondente a $200 \mathrm{~L} \mathrm{ha}^{-}$ ${ }^{1}$. Foram mensurados dados climáticos durante a aplicação dos tratamentos, como temperatura do ar $\left(24,2^{\circ} \mathrm{C}\right)$, umidade relativa do ar $(61,6 \%)$, radiação solar $\left(595,3 \mathrm{w} / \mathrm{m}^{2}\right)$, vento $(2,1 \mathrm{~m} / \mathrm{s})$ e nebulosidade nula. Os vasos foram mantidos em casa de vegetação com irrigação automatizada por aspersão.

Tabela 1. Propriedades químicas e físicas* dos solos utilizados no experimento. Piracicaba (SP), 2009.

\begin{tabular}{|c|c|c|c|c|c|c|c|c|c|c|}
\hline \multicolumn{11}{|c|}{ Propriedades químicas } \\
\hline \multirow{2}{*}{ Solo } & $\mathrm{pH}$ & M.O & P resina & $\mathrm{K}$ & $\mathrm{Ca}$ & $\mathrm{Mg}$ & $\mathrm{Al}$ & CTC & $\mathrm{V}$ & $\mathrm{M}$ \\
\hline & $\mathrm{CaCl}_{2}$ & $\mathrm{~g} \mathrm{dm}^{-3}$ & $\mathrm{mg} \mathrm{dm}^{-3}$ & \multicolumn{5}{|c|}{ mmolc $\mathrm{dm}^{-3}$} & \multicolumn{2}{|c|}{$\%$} \\
\hline Argilo-arenoso $^{(1)}$ & 5,2 & 65 & 99 & 19,4 & 68 & 25 & 2 & 154 & 73 & 2 \\
\hline Arenoso $^{(2)}$ & 5,0 & 10 & 16 & 2,8 & 17 & 7 & 0 & 47 & 57 & 0 \\
\hline \multicolumn{11}{|c|}{ Propriedades físicas } \\
\hline \multirow{3}{*}{ Solo } & \multicolumn{2}{|c|}{ Argila } & \multicolumn{2}{|c|}{ Silte } & \multicolumn{2}{|c|}{ Areia Total } & \multicolumn{2}{|c|}{ Areia Grossa } & \multicolumn{2}{|c|}{ Areia Fina } \\
\hline & \multicolumn{2}{|c|}{$<0,002 \mathrm{~mm}$} & \multicolumn{2}{|c|}{$0,053-0,002 \mathrm{~mm}$} & & & \multicolumn{2}{|c|}{$2,00-0,210 \mathrm{~mm}$} & \multicolumn{2}{|c|}{$0,210-0,053 \mathrm{~mm}$} \\
\hline & \multicolumn{10}{|c|}{$\mathrm{g} \mathrm{kg}^{-1}$} \\
\hline Argilo-arenoso $^{(1)}$ & \multicolumn{2}{|c|}{293} & \multicolumn{2}{|l|}{247} & \multicolumn{2}{|c|}{460} & \multicolumn{2}{|c|}{220} & \multicolumn{2}{|c|}{240} \\
\hline Arenoso $^{(2)}$ & \multicolumn{2}{|c|}{196} & \multicolumn{2}{|l|}{64} & \multicolumn{2}{|c|}{740} & \multicolumn{2}{|c|}{260} & \multicolumn{2}{|c|}{480} \\
\hline
\end{tabular}

* Análise realizada por PIRASOLO Laboratório Agrotécnico Piracicaba Ltda. ${ }^{(1)}$ Textura franco argilo-arenosa. ${ }^{(2)}$ Textura franco arenosa.

Foram realizadas avaliações visuais de controle percentual e massa seca aos 60 DAA. As avaliações de controle foram baseadas em escala visual utilizando-se uma escala de 0 a 100, sendo 0 ausência de controle e 100 controle total da espécie. (ALAM, 1974). A massa seca foi obtida a partir da colheita do material vegetal remanescente da parte aérea das plantas nas parcelas, com posterior secagem em estufa a $70^{\circ} \mathrm{C}$ por $96 \mathrm{~h}$, sendo corrigida para valores percentuais por meio da comparação da massa obtida nos tratamentos herbicidas com a massa da testemunha, considerada $100 \%$.

Os dados foram inicialmente submetidos à aplicação do teste ' $F$ ' na análise da variância.
Quando significativos, os níveis qualitativos (solos) foram comparados pelo teste de 'Tukey' a $1 \%$ de significância. Os níveis do fator herbicida (doses) foram analisados pelo programa estatístico TableCurve 2D v.5.01, com o emprego de regressões não-lineares do tipo log-logístico.

A variável controle foi ajustada ao modelo proposto por Streibig (1988), y = $(\mathrm{a} /(1+(\mathrm{x} / \mathrm{b}) \mathrm{c}))$. Em que, $\mathrm{y}=$ porcentagem de controle; $\mathrm{x}=$ dose do herbicida; $\mathrm{e} \mathrm{a}, \mathrm{b}$ e $\mathrm{c}=$ parâmetros da curva, de modo que a é a diferença entre o ponto máximo e mínimo da curva, b é a dose que proporciona $50 \%$ de resposta da variável e c é a declividade da curva. 
E para a variável massa seca residual, adotou-se o modelo proposto por Seefeldt et al. (1995), y $=$ Pmín $+(\mathrm{a} /(1+(\mathrm{x} / \mathrm{b}) \mathrm{c}))$. Em que, $\mathrm{y}=$ porcentagem residual da massa seca; $\mathrm{x}=$ dose do herbicida; e Pmín, a, b e c = parâmetros da curva, de modo que Pmín é o limite inferior da curva (ponto mínimo), a é a diferença entre o ponto máximo e mínimo da curva, b é a dose que proporciona $50 \%$ de resposta da variável e c é a declividade da curva.

\section{Resultados e Discussão}

A aplicação do teste $F$ na análise da variância indicou a significância (1\%) da interação dose x solo para as duas variáveis avaliadas (controle e massa seca) (Tabela 2).

Tabela 2. Resumo do quadro da análise da variância para plantas de capim-camalote submetidas à aplicação de diferentes doses do herbicida imazapic para as variáveis controle percentual e massa seca residual (\%) aos 60 DAA em solo arenoso e argilo-arenoso. Piracicaba (SP), 2009.

\begin{tabular}{lcccc}
\hline Variável & Fonte de Variação & $\mathrm{GL}^{1}$ & $\mathrm{~F}$ & $\mathrm{Pr}>\mathrm{Fc}$ \\
\hline & Solo arenoso & & & \\
\hline \multirow{3}{*}{ Controle aos 60 DAA } & ${ }^{2}$ & 8 & $100,91^{* * *}$ & 0,000 \\
& Doses (D) & 1 & $45,84^{* *}$ & 0,000 \\
& Solos (S) & 8 & $5,63^{* * *}$ & 0,000 \\
\hline \multirow{3}{*}{ Massa seca aos 60 DAA } & Interação (D*S) & 8 & $81,11^{* *}$ & 0,000 \\
& Doses (D) & 1 & $63,69^{* *}$ & 0,000 \\
& solos (S) & 8 & $12,15^{* *}$ & 0,000 \\
\hline & Interação (D*S) & & & \\
\hline \multirow{2}{*}{ Controle aos 60 DAA ${ }^{3}$} & Solo argilo-arenoso & & $100,91^{* *}$ & 0,000 \\
& Doses (D) & 8 & $45,84^{* *}$ & 0,000 \\
& solos (S) & 1 & $5,63^{* *}$ & 0,000 \\
\hline \multirow{2}{*}{ Massa seca aos 60 DAA } & Interação (D*S) & 8 & $81,11^{* *}$ & 0,000 \\
& Doses (D) & 8 & $63,69^{* *}$ & 0,000 \\
& solos (S) & 1 & $12,15^{* *}$ & 0,000 \\
\hline
\end{tabular}

${ }^{1}$ GL - Graus de liberdade; ${ }^{2}$ Dias após aplicação; ** Significativo à $1 \%$ de probabilidade.

As avaliações de massa seca das plantas demonstraram que a correta escolha da dose de imazapic a ser aplicada deve ser considerada como um ponto importante no manejo da planta daninha capim-camalote, em solos de diferentes texturas. Pode-se observar que no solo arenoso foi observado o menor teor de massa seca em comparação ao solo argiloso, até a dose de 36,75 g i. a. ha ${ }^{-1}$, além da necessidade de menores doses para a obtenção de maior controle da planta daninha em relação ao solo argiloarenoso (Tabela 3 e Figura 1).

Quanto ao controle do capim-camalote, neste experimento, não foram apresentadas as notas de controles visuais aos 60 DAA em função de que algumas plantas, além de estarem completamente deformadas, com meristemas comprometidos $\mathrm{e}$ apenas com as folhas cotiledonares plenamente expandidas, permaneceram vivas até a avaliação de 60 DAA. Isto ocorre porque a fitotoxicidade das plantas afetadas pelos herbicidas inibidores da ALS, como o imazapic, decorre de modo brando, onde poucas horas após o tratamento, o crescimento é estagnado, através da inibição da divisão celular (Rodrigues e Almeida, 2011). De acordo com Carvalho et al. (2006), no campo, observa-se que estas plantas não apresentariam competitividade alguma com a cultura da canade-açúcar e estariam fadadas ao abafamento quando a cultura iniciasse o fechamento da área. Devido a estas observações, o herbicida imazapic, como os dados de massa seca mostram, pode ser viável para aplicação em préemergência para controle da planta daninha capim-camalote. 
Tabela 3. Massa seca residual (\%) aos 60 dias após aplicação (DAA) de diferentes doses de imazapic no controle de capim-camalote. Piracicaba (SP), 2009.

\begin{tabular}{cccc}
\hline \multirow{2}{*}{ Tratamentos } & Doses $\left(\mathrm{g}\right.$ i.a. ha $\left.\mathrm{h}^{-1}\right)$ & \multicolumn{2}{c}{ Massa seca $(\%)$} \\
\cline { 3 - 4 } & & Solo franco arenoso & Franco argilo-arenoso \\
\hline Testemunha & 0,00 & $100,00 \mathrm{a}$ & $100,00 \mathrm{a}$ \\
$1 / 16 \mathrm{D}$ & 9,19 & $50,96 \mathrm{a}$ & $90,65 \mathrm{~b}$ \\
$1 / 8 \mathrm{D}$ & 18,38 & $21,94 \mathrm{a}$ & $94,94 \mathrm{~b}$ \\
$1 / 4 \mathrm{D}$ & 36,75 & $39,69 \mathrm{a}$ & $83,02 \mathrm{~b}$ \\
$1 / 2 \mathrm{D}$ & 73,50 & $28,76 \mathrm{a}$ & $40,17 \mathrm{a}$ \\
$\mathrm{D}$ & 147,00 & $29,02 \mathrm{a}$ & $34,64 \mathrm{a}$ \\
D & 294,00 & $11,19 \mathrm{a}$ & $12,79 \mathrm{a}$ \\
4D & 588,00 & $3,32 \mathrm{a}$ & $4,77 \mathrm{a}$ \\
8D & $1.176,00$ & $4,11 \mathrm{a}$ & $4,10 \mathrm{a}$ \\
\hline CV(\%) & 24,83 \\
DMS & & 14,76 & \\
\hline
\end{tabular}

Médias seguidas por letras iguais, não diferem entre si pelo teste de Tukey com 1\% de significância.
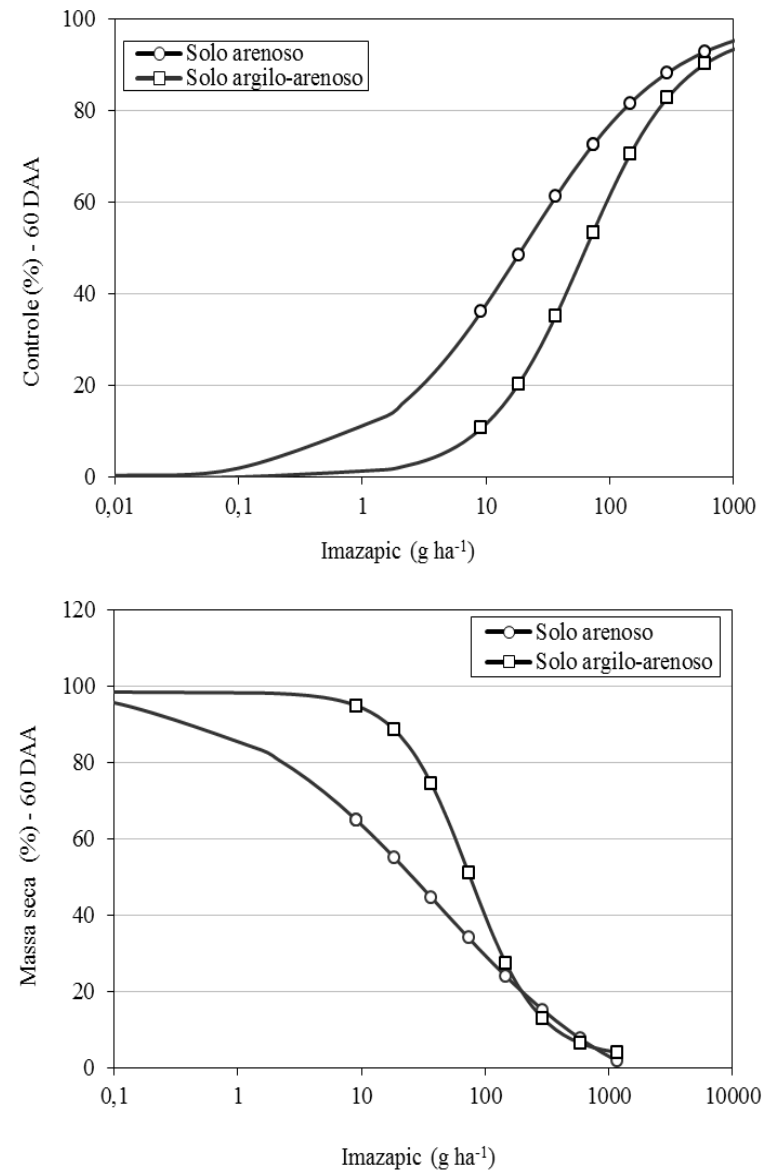

Figura 1. Controle e massa seca percentual de capim-camalote submetida a diferentes doses de imazapic, avaliado aos 60 dias após aplicação (DAA). Piracicaba (SP), 2009.
Para os valores de massa seca aos 60 DAA (Tabela 3), em solo arenoso as doses aplicadas do herbicida imazapic não demonstraram diferença significativa no controle da planta, apesar da dose 18,38 g i.a. $\mathrm{ha}^{-1}$ ter se mostrado mais eficiente em relação a porcentagem de massa seca aos 60 DAA. Já no solo argilo-arenoso as doses requeridas para o maior controle da planta daninha, foram maiores do que a própria dose recomendada de imazapic, sendo o dobro da dose mais eficaz (294 g i.a. ha ${ }^{-}$ ${ }^{1}$ ). Nas doses 588 e 1.176 g i.a. ha ${ }^{-1}$ houve drástica redução da massa seca das plantas em ambos os solos.

Os parâmetros do modelo log-logístico, o coeficiente de determinação e os valores de $\mathrm{C}_{50}$ estão discriminados na Tabela 4 . Os valores de $\mathrm{C}_{50}$ estão em concordância com a discussão anterior, visto que nenhuma das doses exigidas para o controle do capim-camalote excedeu à dose recomendada de imazapic (140 g i. a. ha ${ }^{-1}$ ). $\mathrm{O}$ valor de $\mathrm{C}_{50}$ para o solo argilo-arenoso são superiores aos valores de $\mathrm{C}_{50}$ para o solo arenoso, indicando que para solos com maior teor de argila as doses recomendadas devem ser maiores (Tabela 4).

A textura do solo tem influência direta na eficiência de controle do herbicida imazapic, para solos com maior teor de argila as doses recomendadas devem ser maiores. Como demonstrado por Inoue et al. (2007), em que 
houve maior lixiviação do herbicida imazapic no Latossolo Vermelho distroférrico, que possivelmente possui baixa capacidade de sorção em razão do seu baixo teor de carbono orgânico e argila.

Ligado a este fato o herbicida imazapic, assim como as imidazolinonas em geral, apresenta-se como um herbicida ácido fraco, com moderada a alta solubilidade em água e baixa volatilidade. Sua solubilidade em água bem como sua retenção ao solo dependem do pH deste, em que a máxima adsorção ocorre sob condições ácidas. $\mathrm{O}$ imazapic sendo um herbicida ionizável, se apresenta em duas formas quanto à carga líquida, a molecular, cuja carga líquida é zero em condições de $\mathrm{pH}$ menores que 3,9, e na forma aniônica, quando o
$\mathrm{pH}$ do solo se aproxima da neutralidade (Inoue et al., 2006; Kraemer et al., 2009a; Refatti et al., 2014). Sendo que nestas condições a força de atração entre as moléculas do herbicida diminuem em relação às cargas predominantes no solo (Inoue et al., 2007). Como relatado por Rocha et al. (2000) o grupo químico das imidazolinonas, é pouco sorvido em solos com $\mathrm{pH}$ acima de 3,9, assim, quanto maior o valor do $\mathrm{pH}$ do solo, menor a sorção do imazaquin. Para o imazethapyr verificou-se ligeiro aumento da lixiviação nas condições de solo mais alcalino (Jourdan et al., 1998; Monquero et al., 2008; Kraemer et al., 2009b), podendo limitar a ação do herbicida no banco de sementes de plantas daninhas (Velini, 1992).

Tabela 4. Parâmetros do modelo logístico ${ }^{1}$, coeficiente de determinação $\left(\mathrm{R}^{2}\right), \mathrm{C}_{50}$ para controle e massa seca percentual aos 60 DAA, após aplicação de diferentes doses de imazapic no controle de capim-camalote. Piracicaba (SP), 2009.

\begin{tabular}{ccccccccc}
\hline \multirow{2}{*}{ Espécie } & \multicolumn{2}{c}{ Parâmetros } & \multirow{2}{*}{$\mathrm{R}^{2}$} & \multirow{2}{*}{$\mathrm{F}$} & $\mathrm{C}_{50}$ \\
\cline { 2 - 7 } \cline { 3 - 7 } & Controle (\%) 60 DAA & & & & & & \\
\hline Solo Arenoso & 100,68 & 20,18 & $-0,74$ & - & 0,98 & 294,40 & 19,80 \\
Solo argilo-arenoso & 97,80 & 61,88 & $-1,10$ & - & 0,96 & 77,52 & 64,46 \\
\hline & Massa seca (\%) & & & & & & \\
\hline Solo arenoso & $-14,44$ & 114,44 & 41,64 & 0,54 & 0,98 & 100,04 & 26,00 \\
Solo argilo-arenoso & 2,82 & 95,69 & 74,37 & 1,55 & 0,97 & 53,65 & 75,71 \\
\hline
\end{tabular}

${ }^{1}$ Modelo: $\mathrm{y}=(\mathrm{a} /(1+(\mathrm{x} / \mathrm{b}) \mathrm{c})) ;{ }^{2} \mathrm{DAA}-$ Dias após aplicação.

Além da influência do pH na sorção das moléculas do herbicida, a sorção das imidazolinonas pelos solos é altamente influenciada pelos teores de matéria orgânica e argila, sendo que, os solos com maiores teores de argila ou matéria orgânica requerem maiores doses dos produtos (Miller e Westra, 1998; Christoffoletti et al., 2009; Kraemer et al., 2009b). Como demonstrado na pesquisa pelos teores de matéria orgânica maiores no solo argilo-arenoso $\left(65 \mathrm{~g} \mathrm{dm}^{-3}\right)$ em relação ao solo arenoso $\left(10 \mathrm{~g} \mathrm{dm}^{-3}\right)$ utilizados.

Outras características importantes que devem ser consideradas na correta recomendação de herbicidas são a textura do solo e a quantidade de argila presente neste. De acordo com Silva et al. (2014), no caso da argila
2:1 há maior adsorção de herbicidas devido a maior área superficial específica, já em minerais 1:1, presentes em solos intemperizados de clima tropical e subtrocical, como o Brasil, possuem menor capacidade de expandir-se e de retenção de moléculas, sendo somente cátions nas bordas do mineral. Ainda os óxidos de ferro e alumínio também atuam na sorção de diversos herbicidas, principalmente os ácidos fracos, como as imidazolinonas, e estes minerais encontram-se presentes em grande maioria nos solos brasileiros intemperizados, como os Latossolos. De modo que os óxidos de $\mathrm{Fe}$ e $\mathrm{Al}$ foram as frações de solo que mais se relacionaram com a sorção do imazaquin, demonstrado por Reginato et al. (2001). 


\section{Conclusões}

As doses do herbicida imazapic devem ser recomendadas com base na classe textural dos solos. O solo com maior teor de argila proporcionou menor controle do capimcamalote, pois requer maiores doses para o controle de capim-camalote, sendo o dobro da dose, de 294 g i.a. ha ${ }^{-1}$, a que se apresentou mais eficiente na redução de massa seca aos 60 DAA, já para o solo com menor teor de argila, foi a subdose do herbicida imazapic de 18,38 g i. a. $\mathrm{ha}^{-1}$.

\section{Referências}

Arévalo, R.A. Matoecologia da cana-deaçúcar. São Paulo: Ciba-Geigy, 1979. 16p.

Asociación Latinoamericana de Malezas ALAM. Recomendaciones sobre unificación de los sistemas de evaluación en ensayos de control de malezas. ALAM, v.1, n.1, p.35-38, 1974.

Carvalho, S.J.P.; Moreira, M.S.; Nicolai, M.; López-Ovejero, R.F.; Christoffoleti, P.J.; Medeiros, D. Crescimento e desenvolvimento da planta daninha capim-camalote. Bragantia, v.64, n.4, p.591-600, 2005.

Carvalho, S.J.P.; Nicolai, M.; López-Ovejero, R.F.; Medeiros, D.; Christoffoleti, P.J. Influência de diferentes períodos de seca sobre a eficácia do herbicida imazapic. STAB Açúcar, Álcool e Subprodutos, v.24, n.4, p.4143, 2006.

Christoffoleti, P.J.; Lopez-Ovejero, R.F.; Damin, V.; Carvalho, S.J.P.; Nicolai, M. Comportamento dos herbicidas aplicados ao solo na cultura da cana-de-açúcar. 1. ed. Piracicaba: CP2, 2009. 72 p.

Figueiredo, P.A.M., Ramos, S.B.; Viana, R.S., Lisboa, L.A.M.; Heinrichs, R. Alterações morfoanatômicas foliares da cana-de-açúcar na fase de estabelecimento em condições de matocompetição. Planta Daninha, v.31, n.4, p.777-784, 2013.
Holm, L.G.; Plucknett, D.L.; Pancho, J.V.; Herberger, J.P. The world's worst weeds: Distrbution and biology. Honolulu: The Eastwest Center by the University Press of Hawaii, 1977. 609p.

Inoue, M.H.; Oliveira JR., R.S.; Constantin, J.; Alonso, D.G. Potencial de lixiviação de imazapic e isoxaflutole em colunas de solo. Planta Daninha, v.25, n.3, p.547-555, 2007.

Inoue, M.H.; Oliveira Júnior, R.S.; Constantin, J.; Homem, L.M. Atividade residual de diuron, imazapic e isoxaflutole em dois solos de textura contrastante. In: Congresso Brasileiro da Ciência das Plantas Daninhas, 25., 2006, Brasília. Anais... Brasília: Sociedade Brasileira da Ciência das Plantas Daninhas, 2006. p.130130.

Jourdan, S.W.; Majek, B.A; Ayeni, A.O. Imazethapyr bioactivity and movement in soil. Weed Science, v.46, n.5, p.608-613, 1998.

Kraemer, A.F.; Marchesan, E.; Avila, L.A.; Machado, S.L.O.; Grohs, M. Destino ambiental dos herbicidas do grupo das imidazolinonasrevisão. Planta Daninha, v.27, n.3, p.629-639, 2009a.

Kraemer, A.F.; Marchesan, E.; Grohs, M.; Avila, L.A.; Machado, S.L.O.; Zanella, R. et al. Lixiviação do imazethapyr em solo de várzea sob dois sistemas de manejo. Ciência Rural, v.39, n.6, p.1660-1666, 2009b.

Kuva, M.A.; Gravena, R.; Pitelli, R.A.; Christoffoleti, P.J.; ALVES, P.L.C.A. Períodos de interferência das plantas daninhas na cultura da cana-de-açúcar. III - capimbraquiária (Brachiaria decumbens) e capim-colonião (Panicum maximum). Planta Daninha, v.21, n.1, p.37-44, 2003.

Lorenzi, H. Manual de identificação e controle de plantas daninhas: plantio direto e convencional. 7.ed. Nova Odessa: Instituto Plantarum, 2014. 379p.

Miller, P.; Westra, P. Herbicide behavior in soils. Crop Series - Production. Colorado: Fort 
Collins, 1998. (Colorado State University Cooperative Extension, 562).

Monquero, P.A.; Amaral, L.R.; Binha, D.P.; Silva, A.C.; Silva, P.V. Potencial de lixiviação de herbicidas no solo submetidos a diferentes simulações de precipitação. Planta Daninha, v.26, n.2, p.403-409, 2008.

Oliveira, A.R.; Freitas, S.P. Palha de cana-deaçúcar associada ao herbicida trifloxysulfuron sodium + ametryn no controle de Rottboellia exaltata. Bragantia, v.68, n.1, p.187-194, 2009. Refatti, J.P.; Avila, L.A.; Agostinetto, D.; Manica-Berto, R.; CasBundt, A.; Elgueira, D.B. Efeito da calagem na lixiviação de imazethapyr e imazapyr em solo de cultivo de arroz irrigado. Ciência Rural, v.44, n.6, p.1008-1014, 2014.

Regitano, J.B.; Alleoni, L.R.F.; Tornisielo, V.L. Atributos de solos tropicais e a sorção de imazaquin. Scientia Agricola, v.58, n.4, p.801807, 2001.

Rocha, W.S.D.; Alleoni, L.R.F.; Regitano, J.B.; Casagrande, J.C.; Tornisiello, V.L. Influência do $\mathrm{pH}$ na sorção de imazaquin em um Latossolo Vermelho Acriférrico. Revista Brasileira de Ciência do Solo, v.24, n.3, p.649-655, 2000.

Rodrigues, B.N.; Almeida, F.S. Guia de herbicidas. 6.ed. Londrina: IAPAR, 2011. 697 p.

Seefeldt, S.S.; Jensen, S.E.; Fuerst, E.P. Loglogistic analysis of herbicide dose response relationship. Weed Technology, v.9, n.1, p.218-227,1995.

Silva, A.A.; D’Antonio, L.; Vivian, R.; Oliveira JR., R.S. Comportamento de herbicidas no solo. In: Monquero, P. A. Aspectos da biologia e manejo das plantas daninhas. São Carlos: RiMa Editora, 2014. v.1, cap. 8, p.167-215.

Silva, I.A.B.; Kuva, M.A.; Alves, P.L.C.A.; Salgado, T.P.I. Interferência de uma comunidade de plantas daninhas com predominância de Ipomoea hederifolia na canasoca. Planta Daninha, v.27, n.2, p.265-272, 2009.
Streibig, J.C. Herbicide bioassay. Weed Research, v.28, n.6, p.479-484, 1988.

VELINI, E.D. Comportamento de herbicidas no solo. In: Simpósio Nacional Sobre Manejo De Plantas Daninhas Em Hortali- Ças, 1., 1992, Botucatu. Anais... Botucatu: UNESP, 1992. p.44-64.

Vidal, R.A.; Merotto Jr., A; Schaedler; Lamego, F.P.; Portugal, J.; Menendes, J. et al. Mecanismos de ação dos herbicidas. In: Monquero, P. A. Aspectos da biologia e manejo das plantas daninhas. São Carlos: RiMa Editora, 2014. v.1, cap. 10, p. 235-255.

(2009. 